\title{
REFLEXÕES SOBRE A ASSISTÊNCIA EM ENFERMAGEM À MULHER ENCARCERADA: UM ESTUDO DE REVISÃO INTEGRATIVA
}

\author{
Geovanna Camêlo Souza ${ }^{1}$ \\ Karina Dyanna Salvador Cabral ${ }^{2}$ \\ Cláudia Daniele Barros Leite-Salgueiro ${ }^{3}$
}

\begin{abstract}
SOUZA, G. C.; CABRAL, K. D. S.; LEITE-SALGUEIRO, C. D. B. Reflexões sobre a assistência em enfermagem à mulher encarcerada: um estudo de revisão integrativa. Arq. Cienc. Saúde UNIPAR, Umuarama, v. 22, n. 1, p. 55-62, jan./abr. 2018.

RESUMO: A Enfermagem é uma profissão fundamental quanto à assistência à saúde, a mesma está inserida em diversos locais para prestação de cuidados, incluindo a população carcerária que é marginalizada, mas, também necessita de auxílio à saúde. Este estudo tem como objetivo analisar na literatura, as ações de Educação e Promoção à Saúde da Mulher praticada pela enfermagem, para mulheres privadas de liberdade, com ênfase na fase reprodutiva, no período de pré-natal, parto e puerpério. O método utilizado foi a revisão integrativa da literatura, tendo sido utilizados 18 artigos publicados nas bases SciELO e LILACS, publicados entre os anos de 2012 e 2017. Na análise dos resultados obtidos, os periódicos selecionados discorrem sobre as condições socioeconômicas, condições de saúde, direitos da mulher em cárcere, situação de vivência considerando a complexidade dos casos e a maternidade na prisão. Conclui-se que a vulnerabilidade biopsicossocial das mulheres é potencializada na situação prisional, maximizando os déficits de ações em saúde, sendo o papel da enfermagem importante no que tange às atribuições da profissão, garantindo os direitos dessa população.
\end{abstract}

PALAVRAS-CHAVE: Assistência de Enfermagem. Penitenciária. Saúde da Mulher.

\section{REFLECTIONS ON NURSING ASSISTANCE TO INCARCERATED WOMEN: AN INTEGRATIVE REVIEW}

\begin{abstract}
Nursing is a fundamental profession in health care. It is inserted in several places for the provision of care, including the incarcerated population that is marginalized but also requires health assistance. This study aims to analyze the literature for actions regarding the Education and Promotion of Women's Health practiced by nurses for women deprived of their liberty, with emphasis on the reproductive phase, during the prenatal period, childbirth and puerperium. An integrative review of the literature was carried out using 18 articles published in SciELO and LILACS databases between 2012 and 2017. In the analysis, the selected journals discuss the socioeconomic and health conditions, as well as the rights of women in prison and their living situation considering the complexity of cases and maternity in prison. It can be concluded that the biopsychosocial vulnerability of women is strengthened in the prison situation, maximizing the deficits of health actions. Nurses play an important role in relation to the duties of the profession, guaranteeing the rights of that population.

KEYWORDS: Nursing assistance. Penitentiary. Women's health.
\end{abstract}

\section{Introdução}

O enfermeiro tem um papel fundamental no serviço de saúde, pois é o profissional que administra o serviço, além de realizar o planejamento, organização, coordenação, execução e avaliação da assistência em enfermagem, sua prática para com o usuário é semelhante em todos os contextos, pois o mesmo acolhe o indivíduo, orienta, presta cuidados, acompanha seu estado de saúde, além de articular ações de educação e promoção à saúde a fim de prevenir agravos de acordo com aspectos éticos e legais da profissão (APOLINÁRIO, 2013).

A assistência em enfermagem pode variar de acordo com as condições socioeconômicas da unidade e da comunidade na qual está inserida, havendo dificuldades para prestação de serviço de qualidade, tais como: superlotação, falta de médico e ambiente inadequado, sendo estes problemas existentes também no ambiente prisional (APOLINÁRIO, 2013).

A equipe de enfermagem no sistema prisional poderia funcionar em conjunto com uma equipe multidisciplinar, similar a uma Unidade Básica de Saúde a fim de oferecer um suporte mínimo necessário para atender as particularidades do público feminino, além da consulta de enfermagem para orientar e auxiliar as detentas quanto a outros agravos à saúde e realizar exames como: citopatológico, exame das mamas, consulta pré-natal, puerperal e a puericultura (ASSUNÇÃO, 2014; GIMENES, 2017).

Segundo Lima (2015) enfermeiros de unidade prisional se empenham muito para conseguir prestar assistência adequada, incluindo consultas médicas exames laboratoriais, medicamentos e encaminhamento, percebe-se assim a importância da assistência em enfermagem à saúde da mulher, estando ela em situação de prisão, sendo notável que a saúde devesse funcionar de forma equânime e integral, para este público (ASSUNÇÃO, 2014).

Conhecendo a importância de todos os cidadãos terem o Direito à Saúde, garantidos por lei, o Plano Nacional de Saúde no Sistema Penitenciário (PNSSP), por meio da Portaria Interministerial $\mathrm{n}^{\circ} 1.777$, de 09 de setembro de 2003, inclui a população presidiária no Sistema Único de Saúde (SUS), assegurando sua cidadania na perspectiva dos direitos humanos (LIMA, 2015).

A assistência à saúde no sistema penitenciário brasileiro possui um panorama alarmante, visto que a demanda

DOI: 10.25110/arqsaude.v22i1.2018.6240

${ }^{1}$ Acadêmica em Enfermagem do Instituto Federal de Educação, Ciência e Tecnologia de Pernambuco- IFPE Campus Pesqueira, Pesqueira (PE), Brasil. Endereço: Avenida Félix Paes de Azevedo, 14 - Centro, Buíque- PE, 56520-000. Contato: (87) 9625-0393. Email: geovanna camelo@hotmail.com;

${ }^{2}$ Acadêmica em Enfermagem do Instituto Federal de Educação, Ciência e Tecnologia de Pernambuco - IFPE Campus Pesqueira, Pesqueira (PE), Brasil. Endereço: Rua Abílio de Freitas, 92 - Centenário, Pesqueira- PE, 55200-000. Contato: (87) 9187-6987. Email: karinacabral06@gmail.com;

${ }^{3}$ Psicóloga, Docente Instituto Federal de Educação, Ciência e Tecnologia de Pernambuco - IFPE Campus Pesqueira, Pesqueira (PE), Brasil. Doutoranda em Psicologia Clínica (UNICAP), Mestra em Ciências da Saúde (UPE/FCM), Pós Graduada em Saúde Coletiva (UPE) - Residência (MS/UPE-SES). Endereço: (Departamento de Enfermagem) Rodovia BR-232, Km 208, s/n - Prado, Pesqueira - PE, 55200-000. Contato: (81)9239-7338. Email: claudia.leite@ pesqueira.ifpe.edu.br 
do serviço ofertado é pequena em razão da necessidade da população carcerária a utilizá-lo, dado que este público aumentou consideravelmente nos últimos anos, principalmente o público feminino (PIMENTEL et al., 2015).

"Dados do Departamento Penitenciário Nacional (DEPEN) revelam que a população carcerária masculina brasileira cresceu $130 \%$ entre 2000 e 2012 , enquanto a feminina cresceu $256 \%$ no mesmo período, abrigando 36.039 mulheres em situação carcerária em 2012" (BRASIL, $2013^{4}$ apud PIMENTEL et al., 2015).

Tendo em vista o crescimento da população feminina no sistema penitenciário, boa parte dos perfis encontrados, são de: mulheres jovens, (mães) solteira ou separada, pouca escolaridade, baixo nível socioeconômico, desemprego, pouco acesso aos serviços de saúde, apresentam histórico de Infecções Sexualmente Transmissíveis (IST's), se envolveram com prostituição, e/ou drogas sendo como usuária ou por tráfico. Sendo notável a exclusão social em que as mesmas se encontravam antes da prisão (BARROS et al., 2016; MACEDO et al., 2017).

As mulheres podem adentrar a situação de cárcere, em qualquer etapa do seu ciclo reprodutivo, gestação, parto, puerpério ou amamentação. Independente do contexto sociocultural na qual essa mulher cresceu e se desenvolveu, o ato de "tornar-se mãe" pode realizar mudanças significativas na sua vida, fornecendo crescimento pessoal e emocional (FRANÇA; SILVA, 2016).

Gestantes em regime prisional possuem direitos de acordo com a Lei de Execução Penal (LEP) n $n^{\circ} 7.210$ e $n^{\circ}$ 11.942, assegurando às mulheres ao acompanhamento médico no pré-natal, parto e pós-parto, garantindo assistência de forma integral à saúde da mãe e do bebê, sendo garantidas também condições mínimas estruturais, como dormitórios exclusivos para as gestantes e parturientes e berçários para que auxilie as mães nos cuidados ao recém-nascido até os 6 meses de idade (OLIVEIRA, 2014; FRANÇA, CANTÚ, 2015).

De acordo com o Conselho Nacional de Justiça, somente das 1.420 unidades prisionais brasileiras apenas 48 dispõem de cela ou dormitório adequado para gestantes. O estudo realizado pelo Sistema Integrado de Informações Penitenciárias (Infopen) em 2014 e divulgado pelo Conselho Nacional de Justiça apontou a existência no país de 103 unidades destinadas especificamente para mulheres $(7 \%$ do total), enquanto 1.070 são masculinas (75\%) e 239 são consideradas mistas (17\%), sendo notável que o sistema prisional feminino não está adaptado às necessidades da mulher (BRASİLIA, 2015).

Apesar das Leis garantirem a assistência às mulheres no período gestacional, parto e puerpério, a realidade da maioria das penitenciárias brasileiras não oferecem às detentas auxílio à saúde de forma adequada, em razão de muitas instituições prisionais não possuírem enfermaria, além da superlotação das unidades e estruturas precárias tais como: infiltração e pouca ventilação, proporcionando o ambiente úmido e promovendo o agravo à saúde das mesmas e de seus filhos (PÍCOLI et al., 2014; SILVA et al., 2015).

Embora a saúde, na maioria das penitenciárias femi-

${ }^{4}$ BRASIL. Ministério da Justiça. Departamento Penitenciário Nacional DEPEN. Brasília: Imprensa Nacional. Brasília (DF): Ministério da Justiça, 2013 b. ninas não funcione adequadamente, o cuidado que as mães ofertam aos seus filhos é afetivo, na visão de preservar e promover o bem-estar dos mesmos. Sabendo que as mulheres possuem um papel histórico de cuidadora de seus filhos, inclusive a maioria delas de forma mais participativa e responsável que os homens, quando estão submetidas em cárcere causam prejuízo tanto na desestruturação do lar, quanto no desenvolvimento de seus filhos que passam anos longe da genetriz, o que enfraquece o vínculo do binômio mãe-filho (GIMENES, 2017).

Este estudo justifica-se pela necessidade de ações na atenção à mulher, sob a consideração de integralidade e de "ser biopsicossocial", reconhecendo sua singularidade e importância no núcleo familiar e social, tendo como objetivo, analisar na literatura as ações de Educação e Promoção à Saúde de mulheres privadas de liberdade, com ênfase na fase reprodutiva, nos períodos de pré-natal, parto e puerpério, no sistema prisional. Explorando como é realizada a assistência em enfermagem na promoção à saúde e prevenção de agravos no contexto em que estão inseridas.

\section{Metodologia}

O presente artigo trata de uma revisão integrativa da literatura sobre a assistência à saúde da mulher no sistema prisional. Esta modalidade de pesquisa permite a análise de pesquisas e síntese dos conceitos de forma ampla, tendo em vista a necessidade do conhecimento científico para elaboração e desenvolvimento do artigo. Algumas etapas devem ser seguidas para elaboração da revisão integrativa, sendo elas: Elaboração da pergunta/problemática; coleta bibliográfica, classificação dos dados, análise e discussão dos estudos incluídos, e resultados finais (CROSSETTI, 2012).

A revisão integrativa da literatura é um método que consiste em analisar de forma crítica, estudos anteriores sobre a temática selecionando-os de acordo com as fases organizativas que permitem analisar e avaliar os dados coletados. Devido à alta demanda de informações na área da saúde, se faz necessário a triagem dos artigos subsidiados em evidências comprovadas para pesquisas científicas. A partir desta premissa, a revisão integrativa proporciona uma organização dos resultados mais relevantes das pesquisas (CROSSETTI, 2012).

Por intermédio da revisão integrativa, a pesquisa científica na área da saúde, especialmente no campo da enfermagem, ganhou uma metodologia significativa para a aplicabilidade da Prática Baseada em Evidência (PBE) no contexto social. Este método se distingue das demais metodologias, por ser uma ferramenta altamente articulada e subsidiada em fontes confiáveis (SOUZA; SILVA; CARVALHO, 2010). No caso do presente, fontes brasileiras correspondentes ao tema central.

O tema de interesse e pergunta condutora foi: "Como ocorre a assistência em enfermagem/saúde no sistema penitenciário feminino brasileiro?” A partir de então, foi feita uma busca, ocorrida no mês de abril de 2017, nas bases de dados Latino-Americana e do Caribe em Ciências da Saúde (LILACS) e Scientific Electronic Library Online (SciELO), na modalidade integrada ao Portal Regional da BVS (Biblioteca Virtual de Saúde), os Descritores em Ciências da Saúde (DeCS): Penitenciária; Assistência de Enfermagem; 
Saúde da Mulher.

Elegeu-se as supramencionadas bases de dados devido ao quantitativo de indexação de artigos da área da saúde, também por serem bases que contemplam estudos primários, assim como também, devido à indexação de artigos nas temáticas relacionadas à enfermagem. Os descritores foram ajustados de diferentes maneiras com o objetivo de ampliar a busca pelos estudos. Consideraram-se as variações terminológicas, bem como sinônimos. Foram utilizados para realização de uma busca sensibilizada com o uso dos operadores booleanos AND para ocorrência simultânea de assuntos.

Os operadores booleanos são expressões utilizadas para fazer associações de palavras durante uma pesquisa, os mais utilizados são: AND/ OR/ AND NOT. Podem-se combinar duas ou mais palavras/assuntos no(s) campo(s) de busca, podendo também aprimorar a pesquisa alterando os operadores ou acrescentando descritores (BIREME, 2009).

O Portal Regional da BVS (Biblioteca Virtual de Saúde) engloba várias bases de dados, entre elas, a LILACS, ao acessar o Portal com filtro principal para esta base, pesquisou-se a palavra chave "penitenciária feminina", sendo encontrados 99 artigos, a partir de então, para refinar a pesquisa, foram utilizados os filtros: Texto completo disponível, Assunto Principal: prisões, mulheres, saúde da mulher, gestantes, direitos humanos, direitos a saúde, relações mãe e filho, estresse psicológico, direitos da mulher, saúde mental, enfermagem, totalizando 48 artigos. Foi adicionada a pesquisa, o limite: feminino, país: America do Sul, Brasil, idioma português, assunto: enfermagem, psicologia, restando 6 artigos, na base LILACS.

Os demais periódicos foram pesquisados na base de dados SciELO de forma integrada ao Portal Regional da BVS (Biblioteca Virtual de Saúde), sendo utilizadas as palavras-chave: "Penitenciária Feminina" AND "Assistência em Enfermagem" AND "Saúde da Mulher" na Coleção de periódicos do Brasil, idioma Português, publicados entre os anos de 2012 a 2017, na área de Enfermagem, sendo encontrados um total de 25 artigos.

Considerando os critérios de Inclusão: Artigo completo, texto publicado em português, no período de 2012 a 2017 , totalizaram 31 artigos os quais foram avaliados os resumos e selecionados a partir dos critérios pré-estabelecidos, a partir de então 18 periódicos compuseram a amostra; Sendo excluídos artigos anteriores a 2012, idioma estrangeiro e aqueles que não englobam a temática, a fim de facilitar a coleta de dados realizou-se a tabulação dos artigos estando informações sobre: o número da referência do artigo, nome do autor, ano de publicação, título do artigo, tipo de estudo/ nível de evidência, objetivos e resultados agrupadas em uma tabela para facilitar a visualização.

Outra importante variável considerada foi o nível de evidência científica, esta tem em vista o fortalecimento do processo de Prática Baseada em Evidências, dispondo de sistemas de classificação de evidências caracterizados de forma hierárquica, a partir da abordagem metodológica adotada, a saber: Nível 1: evidências a partir da meta-análise de múltiplos estudos clínicos controlados e randomizados; Nível 2: evidências obtidas em estudos individuais com delineamento experimental; Nível 3: evidências de estudos quase-experimentais; Nível 4: evidências de estudos descritivos (não-experimentais) ou com abordagem qualitativa; Nível 5: evidências provenientes de relatos de caso ou de experiência; Nível 6: evidências baseadas em opiniões de especialistas (SOUZA; SILVA; CARVALHO, 2010).

No presente artigo também foram considerados os preceitos do checklist do PRISMA (2009), metodologia intensamente recomendada e que agrega caráter robusto e protocolar às evidências científicas (GALVÃO; PANSANI; HARRAD2015).

\section{Resultados e Discussão}

A análise dos resultados obtidos está exposta na tabela 1, baseada em um instrumento validado contendo o número da referência do artigo, nome do autor, ano de publicação, título do artigo, tipo de estudo/nível de evidência, objetivos e resultados. A maioria das publicações selecionadas, doze delas, foi encontrada na base de dados SciELO, os demais, na base de dados LILACS (artigos, 2, 3, 8, 9, 12 e 13), sendo publicados entre 2012 e 2017.

Da síntese dos artigos, $22,22 \%$ deles tratam das características socioeconômicas e sociodemográficas das detentas (art. 2, 4, 8 e 12) e 5,55\% (art.13) das características sociodemográficas dos agentes penitenciários e suas condições de saúde; $16,67 \%$ (art. 6,10 e 11) deles tratam da percepção das mulheres encarceradas sobre a assistência à saúde no sistema penitenciário e 11,11\% (art.17 e 18) sobre a percepção dos enfermeiros que prestam assistência nas unidades de sistema fechado; $16,67 \%$ dos artigos (art. 7, $14 \mathrm{e}$ 15) tratam sobre as políticas públicas do sistema carcerário, incluindo a garantia dos direitos à saúde da mulher $11,11 \%$ deles (art. 1 e 5) discorrem sobre a situação de vivência entre elas, considerando a complexidade dos casos e a maternidade na prisão; 16,67\% (art. 3, 9 e 16) tratam da saúde ginecológica das mulheres em regime fechado. 
Tabela 1: Artigos selecionados para revisão integrativa de literatura

\begin{tabular}{|c|c|c|c|c|c|c|}
\hline $\mathbf{N}^{\mathbf{o}}$ & $\begin{array}{c}\text { AUTORES/ } \\
\text { ANO }\end{array}$ & TÍTULO & $\begin{array}{c}\text { AREA DE } \\
\text { PUBLICAÇÃO } \\
\end{array}$ & T.E / N.E.C & OBJETIVOS & RESULTADOS \\
\hline 1 & $\begin{array}{c}\text { FRANÇA, } \\
\text { Leandro Ayres; } \\
\text { CANTÚ, } \\
\text { Mariana Coelho, } \\
2015 .\end{array}$ & $\begin{array}{l}\text { Condições } \\
\text { processo e } \\
\text { experiência do } \\
\text { encarceramento } \\
\text { feminino: } \\
\text { uma pesquisa } \\
\text { de campo na } \\
\text { Penitenciária } \\
\text { Femininado } \\
\text { Paraná }\end{array}$ & Direito & $\begin{array}{c}\text { Estudo de } \\
\text { Campo/Nível } \\
\text { de Evidência } \\
\text { Científica - } 5\end{array}$ & $\begin{array}{l}\text { Analisar o processo } \\
\text { e as condições } \\
\text { da vivência de } \\
\text { presidiárias no } \\
\text { cárcere, considerando } \\
\text { sua complexidade. }\end{array}$ & $\begin{array}{l}\text { A pesquisa evidenciou } \\
\text { que o cárcere gera con- } \\
\text { sequências negativas } \\
\text { nas apenadas, apesar } \\
\text { de poder ser resolvidos } \\
\text { com uma boa gestão pri- } \\
\text { sional, elas devem rece- } \\
\text { ber um tratamento dife- } \\
\text { renciado do homem en- } \\
\text { carcerado, considerando } \\
\text { suas particularidades de } \\
\text { gênero comportamento, } \\
\text { personalidade, } \\
\text { mentos e sexo. }\end{array}$ \\
\hline 2 & $\begin{array}{l}\text { PÍCOLI, Renata } \\
\text { Polópoli et al., } \\
2014 .\end{array}$ & $\begin{array}{c}\text { Gestação E } \\
\text { Puerpério No } \\
\text { Cárcere: Estudo } \\
\text { Descritivo Da } \\
\text { Atenção À Saúde }\end{array}$ & Saúde Pública & $\begin{array}{c}\text { Estudo } \\
\text { transversal/Nível } \\
\text { de Evidência } \\
\text { Científica - } 3\end{array}$ & $\begin{array}{c}\text { Descrever } \\
\text { características } \\
\text { sociodemográficas, } \\
\text { assistência ao pré- } \\
\text { natal e puerpério em } \\
\text { detentas. }\end{array}$ & $\begin{array}{l}\text { A assistência pré-natal e } \\
\text { puerperal disponível no } \\
\text { presídio revelou-se ina- } \\
\text { dequada em relação aos } \\
\text { critérios estabelecidos } \\
\text { pelo Programa Nacional } \\
\text { de Humanização do Pré- } \\
\text {-Natal e Nascimento. }\end{array}$ \\
\hline 3 & $\begin{array}{l}\text { FOCHI, Maria } \\
\text { do Carmo Silva } \\
\text { et al., } 2014 .\end{array}$ & $\begin{array}{c}\text { Pré-natal em } \\
\text { unidade básica de } \\
\text { saúde a gestantes } \\
\text { em situação } \\
\text { prisional }\end{array}$ & Enfermagem & $\begin{array}{l}\text { Relato de } \\
\text { Experiência/ } \\
\text { Nível de } \\
\text { Evidência } \\
\text { Científica - } 5\end{array}$ & $\begin{array}{l}\text { Descrever a } \\
\text { assistência pré- natal } \\
\text { realizada em uma } \\
\text { UBS do interior do } \\
\text { estado de São Paulo, } \\
\text { ofertada à população } \\
\text { carcerária feminina. }\end{array}$ & $\begin{array}{l}\text { A assistência oferecida } \\
\text { às gestantes permitiu } \\
\text { conhecer o universo } \\
\text { pluralizado da presidiá- } \\
\text { ria, considerando a im- } \\
\text { portância ao atendimen- } \\
\text { to à saúde da população } \\
\text { carcerária, evitando } \\
\text { agravos físicos, emo- } \\
\text { cionais e sociais, que na } \\
\text { gestante, pode se esten- } \\
\text { der à sua prole. }\end{array}$ \\
\hline 4 & $\begin{array}{l}\text { MACEDO, } \\
\text { Flávia Ribeiro } \\
\text { Martins et al., } \\
2017 .\end{array}$ & $\begin{array}{c}\text { Perfil } \\
\text { Socioeconômico } \\
\text { E Saúde } \\
\text { Ginecológica De } \\
\text { Presidiárias }\end{array}$ & Enfermagem & $\begin{array}{c}\text { Estudo } \\
\text { descritivo, } \\
\text { transversal/Nível } \\
\text { de Evidência } \\
\text { Científica - } 4\end{array}$ & $\begin{array}{l}\text { Identificar o perfil } \\
\text { socioeconômico } \\
\text { e ginecológico de } \\
\text { mulheres detidas em } \\
\text { regime fechado. }\end{array}$ & $\begin{array}{l}\text { O direito à saúde, garan- } \\
\text { tido por lei a todos os } \\
\text { presidiários no Brasil, } \\
\text { mostra-se uma realidade } \\
\text { ainda distante do siste- } \\
\text { ma prisional, uma vez } \\
\text { que há evidentes falhas } \\
\text { na assistência prestada } \\
\text { às mulheres observadas } \\
\text { no estudo. }\end{array}$ \\
\hline 5 & $\begin{array}{c}\text { FRANÇA, Alba } \\
\text { Maria Bomfim } \\
\text { de; SILVA, } \\
\text { Jovânia Marques } \\
\text { de Oliveira e, } \\
2016 .\end{array}$ & $\begin{array}{l}\text { A Mulher Em } \\
\text { Situação De } \\
\text { Prisão E A } \\
\text { Vivência Da } \\
\text { Maternidade }\end{array}$ & Enfermagem & $\begin{array}{c}\text { Estudo } \\
\text { descritivo/Nível } \\
\text { de Evidência } \\
\text { Científica }-4\end{array}$ & $\begin{array}{l}\text { Compreender } \\
\text { como as mulheres } \\
\text { em situação de } \\
\text { prisão vivenciam a } \\
\text { maternidade durante } \\
\text { a reclusão. }\end{array}$ & $\begin{array}{l}\text { A partir de seus relatos, } \\
\text { pode-se compreender } \\
\text { como as mulheres em } \\
\text { reclusão vivenciaram a } \\
\text { maternidade nesse perí- } \\
\text { odo, sendo considerado } \\
\text { negativo para as mães e } \\
\text { uma problemática para } \\
\text { os profissionais de saú- } \\
\text { de e gestores. }\end{array}$ \\
\hline
\end{tabular}




\begin{tabular}{|c|c|c|c|c|c|c|}
\hline 6 & $\begin{array}{c}\text { PIMENTEL, } \\
\text { Itaciara dos } \\
\text { Santos et al., } \\
2015 .\end{array}$ & $\begin{array}{c}\text { Percepção } \\
\text { de mulheres } \\
\text { privadas de } \\
\text { liberdade acerca } \\
\text { da assistência à } \\
\text { saúde no sistema } \\
\text { penitenciário }\end{array}$ & Saúde Pública & $\begin{array}{c}\text { Pesquisa } \\
\text { qualitativa/ Nível } \\
\text { de Evidência }-5\end{array}$ & $\begin{array}{c}\text { Conhecer a } \\
\text { percepção das } \\
\text { mulheres sobre a } \\
\text { assistência à saúde } \\
\text { no sistema prisional } \\
\text { analisando sob o } \\
\text { Plano Nacional de } \\
\text { Saúde no Sistema } \\
\text { Penitenciário. } \\
\end{array}$ & $\begin{array}{l}\text { Embora algumas ações } \\
\text { em saúde estejam de } \\
\text { acordo com o Plano } \\
\text { Nacional, a assistên- } \\
\text { cia à saúde no sistema } \\
\text { penitenciário ainda há } \\
\text { muito a melhorar, para } \\
\text { a efetivação de uma boa } \\
\text { assistência. }\end{array}$ \\
\hline 7 & $\begin{array}{c}\text { ASSUNÇÃO, } \\
\text { Cória Helena } \\
\text { Vieira de, } 2014 .\end{array}$ & $\begin{array}{l}\text { A Saúde da } \\
\text { mulher: a } \\
\text { situação das } \\
\text { encarceradas } \\
\text { do Presídio } \\
\text { Feminino de } \\
\text { Florianópolis }\end{array}$ & Serviço Social & $\begin{array}{c}\text { Pesquisa } \\
\text { de Campo- } \\
\text { Exploratório/ } \\
\text { Nível de } \\
\text { Evidência } \\
\text { Científica - } 1\end{array}$ & $\begin{array}{l}\text { Conhecer as políticas } \\
\text { públicas na área de } \\
\text { saúde no sistema } \\
\text { prisional em especial } \\
\text { a saúde da mulher } \\
\text { encarcerada. }\end{array}$ & $\begin{array}{l}\text { Pessoas privadas de li- } \\
\text { berdade não devem ser } \\
\text { privadas do direito à } \\
\text { saúde, Precisando ha- } \\
\text { ver pactuação entre as } \\
\text { políticas públicas e pro- } \\
\text { fissionais de saúde para } \\
\text { que possam oferecer um } \\
\text { olhar para a situação em } \\
\text { que a mulher se encon- } \\
\text { tra. }\end{array}$ \\
\hline 8 & $\begin{array}{c}\text { BARROS, Maria } \\
\text { Aline Rodrigues } \\
\text { et al., } 2016 .\end{array}$ & $\begin{array}{c}\text { Situação } \\
\text { socioeconômica } \\
\text { e reprodutiva } \\
\text { de mulheres } \\
\text { presidiárias }\end{array}$ & Enfermagem & $\begin{array}{c}\text { Estudo } \\
\text { descritivo/ Nível } \\
\text { de Evidência } \\
\text { Científica }-4\end{array}$ & $\begin{array}{l}\text { Investigar o perfil } \\
\text { socioeconômico } \\
\text { e reprodutivo de } \\
\text { presidiárias }\end{array}$ & $\begin{array}{l}\text { Observou-se a neces- } \\
\text { sidade de planejar es- } \\
\text { tratégias educacionais } \\
\text { de promoção da saúde } \\
\text { reprodutiva que englo- } \\
\text { bam as peculiaridades } \\
\text { sociais vivenciadas. }\end{array}$ \\
\hline 9 & $\begin{array}{c}\text { RIBEIRO, } \\
\text { Samila Gomes et } \\
\text { al., } 2013 .\end{array}$ & $\begin{array}{l}\text { Perfil gineco- } \\
\text { obstétrico } \\
\text { de mulheres } \\
\text { encarceradas no } \\
\text { estado do Ceará }\end{array}$ & Enfermagem & $\begin{array}{l}\text { Estudo } \\
\text { documental/ } \\
\text { Nível de } \\
\text { Evidência } \\
\text { Científica - 5 }\end{array}$ & $\begin{array}{l}\text { Identificar o perfil } \\
\text { gineco-obstétrico } \\
\text { de mulheres } \\
\text { encarceradas no } \\
\text { Ceará }\end{array}$ & $\begin{array}{l}\text { Os dados evidenciaram } \\
\text { um número elevado de } \\
\text { gestações e abortamen- } \\
\text { tos. Enfatizando a ne- } \\
\text { cessidade de ações de } \\
\text { saúde que específicas } \\
\text { para o contexto prisio- } \\
\text { nal, pois as detentas } \\
\text { apresentam riscos gine- } \\
\text { co-obstétricos. }\end{array}$ \\
\hline 10 & $\begin{array}{l}\text { DA ROCHA, } \\
\text { Luciano Chaves } \\
\text { Dutra et al., } \\
2014 .\end{array}$ & $\begin{array}{c}\text { Percepção } \\
\text { Das Mulheres } \\
\text { Encarceradas Em } \\
\text { Penitenciária Em } \\
\text { Relação a Saúde } \\
\text { da Mulher }\end{array}$ & Enfermagem & $\begin{array}{c}\text { Estudo descritivo } \\
\text { exploratório/ } \\
\text { Nível de } \\
\text { Evidência } \\
\text { Científica - } 4\end{array}$ & $\begin{array}{l}\text { Conhecer a } \\
\text { percepção } \\
\text { de mulheres } \\
\text { encarceradas em } \\
\text { penitenciária em } \\
\text { relação à atenção a } \\
\text { Saúde da Mulher. }\end{array}$ & $\begin{array}{l}\text { O material obtido per- } \\
\text { mitiu identificar as ne- } \\
\text { cessidades no qual se } \\
\text { insere a saúde das pre- } \\
\text { sidiárias, apesar de ser } \\
\text { um grupo marginalizado } \\
\text { pela sociedade, a equipe } \\
\text { de enfermagem conhece } \\
\text { a realidade social a qual } \\
\text { elas vivem e prestam } \\
\text { uma boa assistência. }\end{array}$ \\
\hline 11 & $\begin{array}{l}\text { SILVA, } \\
\text { Monnyque } \\
\text { Marques et } \\
\text { al.,2015. }\end{array}$ & $\begin{array}{l}\text { Percepção das } \\
\text { mulheres sobre a } \\
\text { assistência pré- } \\
\text { natal prestada } \\
\text { na colônia penal } \\
\text { feminina }\end{array}$ & Enfermagem & $\begin{array}{l}\text { Estudo descritivo } \\
\text { Transversal/ } \\
\text { Nível de } \\
\text { Evidência } \\
\text { Científica - } 4\end{array}$ & $\begin{array}{c}\text { Investigar a } \\
\text { percepção das } \\
\text { mulheres sobre a } \\
\text { assistência pré-natal } \\
\text { prestada na Colônia } \\
\text { Penal Feminina do } \\
\text { Recife. }\end{array}$ & $\begin{array}{l}\text { As detentas revelaram } \\
\text { falha na troca de infor- } \\
\text { mações e esclarecimen- } \\
\text { to de dúvidas durante } \\
\text { as consultas e entre os } \\
\text { profissionais, estes re- } \\
\text { conheceram a impor- } \\
\text { tância do pré-natal para } \\
\text { um parto seguro, e para } \\
\text { saúde da mãe e do bebê. }\end{array}$ \\
\hline
\end{tabular}




\begin{tabular}{|c|c|c|c|c|c|c|}
\hline 12 & $\begin{array}{c}\text { NICOLAU, Ana } \\
\text { Izabel Oliveira et } \\
\text { al.,2012. }\end{array}$ & $\begin{array}{l}\text { Retrato da } \\
\text { realidade } \\
\text { socioeconômica } \\
\text { e sexual de } \\
\text { mulheres } \\
\text { presidiárias }\end{array}$ & Enfermagem & $\begin{array}{c}\text { Estudo } \\
\text { transversal/Nível } \\
\text { de Evidência } \\
\text { Científica }-5\end{array}$ & $\begin{array}{c}\text { Investigar o perfil } \\
\text { socioeconômico e } \\
\text { sexual de presidiárias }\end{array}$ & $\begin{array}{l}\text { Diante das vulnerabi- } \\
\text { lidades encontradas } \\
\text { concluiu-se que as es- } \\
\text { tratégias de promoção } \\
\text { da saúde sexual em am- } \\
\text { biente prisional devem } \\
\text { englobar a complexida- } \\
\text { de das peculiaridades } \\
\text { vivenciadas pelas presi- } \\
\text { diárias. }\end{array}$ \\
\hline 13 & $\begin{array}{l}\text { GRECO, Patrícia } \\
\text { Bitencourt } \\
\text { Toscani et al., } \\
2013 .\end{array}$ & $\begin{array}{c}\text { Estresse No } \\
\text { Trabalho Em } \\
\text { Agentes Dos } \\
\text { Centros de } \\
\text { Atendimento } \\
\text { Socioeducativo } \\
\text { do Rio Grande } \\
\text { do Sul }\end{array}$ & Enfermagem & $\begin{array}{c}\text { Estudo } \\
\text { Transversal/ } \\
\text { Nível de } \\
\text { Evidência } \\
\text { Científica - } 4\end{array}$ & $\begin{array}{l}\text { Associar o estresse } \\
\text { no trabalho, com } \\
\text { características } \\
\text { sociodemográficas, } \\
\text { hábitos e condições } \\
\text { de saúde dos agentes. }\end{array}$ & $\begin{array}{l}\text { Há necessidade de bus- } \\
\text { car melhores condições } \\
\text { de trabalho e a efetiva- } \\
\text { ção de um Serviço de } \\
\text { Saúde do Trabalhador } \\
\text { atuante, no sentido de } \\
\text { minimizar os efeitos das } \\
\text { demandas psicológicas } \\
\text { no trabalho do agente } \\
\text { socioeducador. }\end{array}$ \\
\hline 14 & $\begin{array}{c}\text { GIMENES, } \\
\text { Nathália } \\
\text { Fernandes } 2017 .\end{array}$ & $\begin{array}{c}\text { A Realidade Da } \\
\text { Maternidade No } \\
\text { Sistema Prisional } \\
\text { Brasileiro }\end{array}$ & Saúde Pública & $\begin{array}{l}\text { Estudo } \\
\text { Documental/ } \\
\text { Nível de } \\
\text { Evidência } \\
\text { Científica - } 5\end{array}$ & $\begin{array}{l}\text { Apresentar a situação } \\
\text { do sistema carcerário } \\
\text { desde a sua origem, } \\
\text { além de certificar a } \\
\text { respeito da existência } \\
\text { dos direitos das } \\
\text { encarceradas. }\end{array}$ & $\begin{array}{l}\text { Certificou-se que existe } \\
\text { uma falta de assistência } \\
\text { à saúde nas unidades pe- } \\
\text { nitenciárias, com Ênfase } \\
\text { no momento do parto e } \\
\text { no pós-parto, os bebês } \\
\text { ficam com as mães por } \\
\text { seis meses, após isso } \\
\text { devem sair da peniten- } \\
\text { ciária. }\end{array}$ \\
\hline 15 & $\begin{array}{l}\text { LIMA, Jaqueline } \\
\text { Ferreira, } 2015 .\end{array}$ & $\begin{array}{l}\text { Direito à saúde } \\
\text { das mulheres } \\
\text { gestantes e } \\
\text { puérperas } \\
\text { no Sistema } \\
\text { Penitenciário } \\
\text { Feminino do } \\
\text { Distrito Federal }\end{array}$ & Saúde Coletiva & $\begin{array}{l}\text { Estudo } \\
\text { Documental/ } \\
\text { Nível de } \\
\text { Evidência } \\
\text { Científica - } 5\end{array}$ & $\begin{array}{l}\text { Identificar as ações } \\
\text { e serviços de saúde } \\
\text { necessários para } \\
\text { garantir o direito à } \\
\text { saúde das mulheres } \\
\text { encarceradas, e como } \\
\text { ele é garantido. }\end{array}$ & $\begin{array}{l}\text { Verificaram-se as apli- } \\
\text { cabilidades, os pontos } \\
\text { que deveriam ser mais } \\
\text { explorados e a articu- } \\
\text { lação dos profissionais } \\
\text { junto com os respon- } \\
\text { sáveis pela população } \\
\text { privada de liberdade vi- } \\
\text { sando a solução das pro- } \\
\text { blemáticas levantadas. }\end{array}$ \\
\hline 16 & $\begin{array}{c}\text { OLIVEIRA, } \\
\text { Rayane Noronha, } \\
2014 .\end{array}$ & $\begin{array}{l}\text { Mulheres, saúde } \\
\text { reprodutiva } \\
\text { e prisão: um } \\
\text { estudo da } \\
\text { maternidade em } \\
\text { uma perspectiva } \\
\text { feminista na } \\
\text { Penitenciária } \\
\text { feminina }\end{array}$ & Serviço Social & $\begin{array}{l}\text { Pesquisa de } \\
\text { Campo/ Nível } \\
\text { de Evidência } \\
\text { Científica - } 5\end{array}$ & $\begin{array}{l}\text { Analisar a saúde } \\
\text { reprodutiva das } \\
\text { gestantes e com filhas } \\
\text { na Penitenciária, } \\
\text { sob uma perspectiva } \\
\text { feminista. }\end{array}$ & $\begin{array}{l}\text { A essência de ser mu- } \\
\text { lher se manifesta na ma- } \\
\text { ternidade, a condição de } \\
\text { "bandida" para as mu- } \\
\text { lheres que estão sob a } \\
\text { tutela do Estado em ins- } \\
\text { tituições prisionais não } \\
\text { é suspensa no momento } \\
\text { dos seus processos de } \\
\text { parto. }\end{array}$ \\
\hline 17 & $\begin{array}{l}\text { APOLINARIO, } \\
\text { Fernando } \\
\text { Henrique, } 2013 .\end{array}$ & $\begin{array}{c}\text { Significados } \\
\text { Atribuídos Por } \\
\text { Enfermeiros } \\
\text { À Assistência } \\
\text { Que Prestam } \\
\text { A Indivíduos } \\
\text { Em Situação } \\
\text { Prisional }\end{array}$ & Enfermagem & $\begin{array}{l}\text { Pesquisa Quali- } \\
\text { Quantitativa/ } \\
\text { Nível de } \\
\text { Evidência } \\
\text { Científica - } 4\end{array}$ & $\begin{array}{l}\text { Caracterizar e } \\
\text { identificar as } \\
\text { percepções e } \\
\text { significados } \\
\text { atribuídos por } \\
\text { enfermeiros que } \\
\text { prestam assistência } \\
\text { nas unidades de } \\
\text { sistema fechado }\end{array}$ & $\begin{array}{l}\text { Há desafios e dificulda- } \\
\text { des enfrentadas pelos } \\
\text { enfermeiros na presta- } \\
\text { ção de assistência ao } \\
\text { apenado, visto que a } \\
\text { superlotação, falta de } \\
\text { médicos, dificuldade na } \\
\text { referência e contrarrefe- } \\
\text { rência, além da insegu- } \\
\text { rança em trabalhar, as } \\
\text { condições de trabalho } \\
\text { são desfavoráveis para } \\
\text { um melhor atendimento. }\end{array}$ \\
\hline
\end{tabular}




\begin{tabular}{|c|c|c|c|c|c|c|}
\hline 18 & $\begin{array}{l}\text { SILVA, Elaine } \\
\text { Mara da., } 2013 .\end{array}$ & $\begin{array}{l}\text { A mulher detenta, } \\
\text { a sua saúde } \\
\text { sexual e sua } \\
\text { sexualidade: } \\
\text { revisão } \\
\text { sistemática } \\
\text { da literatura } \\
\text { brasileira sobre } \\
\text { atuação da } \\
\text { enfermagem } \\
\text { neste processo. }\end{array}$ & Enfermagem & $\begin{array}{c}\text { Estudo de } \\
\text { Revisão } \\
\text { Integrativa/Nível } \\
\text { de Evidência } \\
\text { Científica - } 1\end{array}$ & $\begin{array}{l}\text { Refletir sobre a } \\
\text { literatura, se há } \\
\text { contribuições de } \\
\text { enfermagem na saúde } \\
\text { sexual, reprodutiva } \\
\text { e sexualidade das } \\
\text { detentas, tendo em } \\
\text { vista a precariedade } \\
\text { e risco de IST's que } \\
\text { as mesmas estão } \\
\text { expostas na prisão. }\end{array}$ & $\begin{array}{l}\text { Apesar da grande de- } \\
\text { manda do público, a } \\
\text { equipe de enfermagem } \\
\text { faz o possível para aten- } \\
\text { der, orientar e tratar a } \\
\text { respeito da saúde sexual } \\
\text { e sexualidade das mu- } \\
\text { lheres, porém seus direi- } \\
\text { tos são desrespeitados } \\
\text { perante a omissão da } \\
\text { administração da Uni- } \\
\text { dade prisional perante o } \\
\text { Estado. }\end{array}$ \\
\hline
\end{tabular}

A análise literária permitiu identificar que os perfis das mulheres apenadas são de jovens, com baixa escolaridade e com condições socioeconômicas precárias, que iniciam a vida sexual imaturamente, se expondo a IST's e gravidez de risco, constituindo um grupo vulnerável antes de entrarem na prisão e agravando-se após o encarceramento. Devido a estes fatores, ressalta-se a importância da assistência à saúde de qualidade (RIBEIRO et al., 2013).

As mulheres, parturientes e seus filhos em situação de cárcere, estão mais vulneráveis à doenças infecciosas, oportunistas e crônicas, visto que a maioria dos presídios não dispõem de estrutura adequada com condições mínimas de limpeza, higiene pessoal e alimentação precária, bem como pouca ventilação, umidade e superlotação (FRANÇA; CANTÚ, 2015).

Boa parte dos serviços de saúde nas unidades prisionais é escasso, não contando com uma equipe multidisciplinar composta pelo profissional médico, enfermeiro, técnico em enfermagem, nutricionista e assistência social para proporcionar assistência à saúde de qualidade. $\mathrm{O}$ panorama real, conta apenas com enfermeiro e técnico em enfermagem, que prestam cuidados diários. Quanto ao profissional médico, o atendimento é mensal ou quinzenal, dependendo da unidade (APOLINÁRIO, 2013).

Considerando que em muitos presídios não existe um espaço físico adequado para o atendimento das clientes em questão, contribuindo para que a equipe de enfermagem preste um atendimento à saúde ineficaz, incluindo o receio quanto à segurança, também existe o preconceito de alguns profissionais com relação às mulheres, ou por serem detentas ou homoafetivas, levando a uma desumanização do cuidado e da prestação de serviço adequado (SILVA, 2013; APOLINÁRIO, 2013).

Sob a ótica das detentas que utilizam os serviços de saúde oferecidos pela unidade prisional, principalmente as que realizam acompanhamento da sua gestação do pré-natal, pós-parto e puerpério na unidade, muitas julgam que não existe acolhimento por parte dos profissionais e do sistema em geral, visto que quando há a necessidade de deslocamento, existe uma dificuldade nesse processo, aumentando o sofrimento da mãe e do feto/bebê (PIMENTEL et al., 2015).

\section{Conclusão}

A pesquisa permitiu observar que a vulnerabilidade biopsicossocial das mulheres é potencializada na situação prisional, além de maximizar os déficits de saúde pública, sendo estes, referentes a ações de prestação do cuidado e assistência à saúde das detentas, pois apesar da existência de cobertura legislativa que garante direitos plenos na atenção integral à saúde dos indivíduos encarcerados, baseado nos princípios da Universalidade, Integralidade e Equidade do Sistema Único de Saúde (SUS) de e nos direitos humanos.

Foi possível identificar a importância da construção da relação mãe/filho e fortalecimento desses laços/vínculos, que são fundamentais para a saúde, tanto da criança quanto da mãe, e que devem ser estimulados desde o pré-natal. Bem como, a saúde das presidiárias de modo geral, de receber assistência plena. Partindo desta premissa, a equipe de saúde, em especial a enfermagem, uma vez que estão mais próximos da rotina destas gestantes e parturientes, devem prestar atendimento equânime e integral às pacientes em situação prisional, sem qualquer preconceito ou exclusão.

Desta forma, o papel da enfermagem é de suma importância no que tange às atribuições da profissão, além de garantir os direitos desta população e atenuar as falhas do sistema de saúde dos presídios. A preparação destes profissionais para a vivência desta situação pouco comum se faz imprescindível para o contato com o público encarcerado, posto que a captação, o acolhimento, a orientação e as ações de prevenção e promoção da saúde destas mulheres, são vitais para minimizar os agravos de saúde das mesmas em qualquer período da vida. Com isto, o enfermeiro abstrai a condição situacional do detento, identificando-o como ser humano carente de cuidados à saúde.

\section{Referências}

\section{APOLINÁRIO, F. H. Significados atribuídos por} enfermeiros à assistência que prestam a indivíduos em situação prisional. 2013. 140 f. Dissertação (Mestre em Enfermagem) - Universidade Estadual Paulista - UNESP, Botucatu, 2013.

ASSUNÇÃO, C. H. V. D. A saúde da mulher: a situação das encarceradas do Presídio Feminino de Florianópolis. 2014. 64 f. Trabalho de Conclusão de Curso (Graduação em Serviço Social) - Universidade Federal de Santa Catarina, Florianópolis, 2014.

BARROS, M. A. R. et al. Situação socioeconômica e reprodutiva de mulheres presidiárias. Sociodemographic and reproductive factors of female prisoners. Rev Fund Care Online, v. 8, n. 4, p. 4980-4985, 2016. 
BIREME (Brasil) Biblioteca Virtual em Saúde - Tutorial de Pesquisa Bibliográfica. / São Paulo: 2009. 24 p. Disponível em: <http://bvsms.saude.gov.br/bvs/publicacoes/apostila biblioteca_virtual_saude_reduzida.pdf $>$. Acesso em: 09 jun. 2017.

CROSSETTI, M. G. O. Revisão integrativa de pesquisa na enfermagem: o rigor científico que lhe é exigido. Revista gaúcha de enfermagem, v. 33, n. 2, p. 8-13, 2012.

FERNANDES, W. População carcerária feminina aumentou $567 \%$ em 15 anos no Brasil. Conselho Nacional de Justiça. Brasília. 2015. Disponível em: <http:// www.cnj.jus.br/noticias/cnj/80853-populacao-carcerariafeminina-aumentou-567-em-15-anos-no-brasil > . Acesso em: 21 abr. 2017.

FRANÇA, A. M. B. D.; SILVA, J. M. D. O. E. A mulher em situação de prisão e a vivência da maternidade. Revista de enfermagem UFPE, v. 10, n. 5, p. 1891-1894, 2016.

FRANÇA, L. A.; CANTÚ, M. C. Condições, processo e experiência do encarceramento feminino: uma pesquisa de campo na Penitenciária Feminina do Paraná. Direito e Democracia, Canoas, v. 16, n. 2, p. 63-85, 2015.

GALVÃO, T. F.; PANSANI, T. D. S. A.; HARRAD, D. Principais itens para relatar revisões sistemáticas e metaanálises: a recomendação PRISMA. Epidemiol. Serv. Saúde, v. 24, n. 2, p. 335-342, 2015.

GIMENES, N. F. A realidade da maternidade no sistema prisional brasileiro. 2016. $96 \mathrm{f}$. Monografia (Bacharel em Direito) - Centro Universitário Antonio Eufrásio de Toledo de Presidente Prudente, São Paulo. 2016.

RIBEIRO, S. G. et al. Perfil gineco-obstétrico de mulheres encarceradas no estado do Ceará. Text Context Nursing, v. 22, n. 1, p. 13-21, 2013.

LIMA, J. F. O direito à saúde das mulheres gestantes e puérperas no Sistema Penitenciário Feminino do Distrito Federal. 2015. 62 f. Trabalho de Conclusão de Curso (Bacharel em Saúde Coletiva) - Universidade de Brasília, Brasília, 2015.

MACEDO, F. R. M. et al. Perfil socioeconômico e saúde ginecológica de presidiárias. SANARE - Revista de Políticas Públicas, v. 15, n. 2, p. 30-36, 2016.

OLIVEIRA, R. N. Mulheres, saúde reprodutiva e prisão: um estudo da maternidade em uma perspectiva feminista na Penitenciária Feminina do Distrito Federal. 2014. 72 f. Trabalho de Conclusão de Curso (Bacharel em Serviço Social) - Universidade de Brasília, Brasília, 2014.

PÍCOLI, R. P. et al. Gestação e puerpério no cárcere: estudo descritivo da atenção à saúde. Revista Baiana de Saúde Pública, v. 38, n. 1, p. 67-82, 2014.

PIMENTEL, I. D. S. et al. Percepção de mulheres privadas de liberdade acerca da assistência à saúde no sistema penitenciário. Revista Interdisciplinar, v. 8, n. 4, p. 109$119,2015$.

SILVA, E. M. da. A mulher detenta, a sua saúde sexual e sua sexualidade: revisão sistemática da literatura brasileira sobre atuação da enfermagem neste processo. 2013. 145 f. Dissertação (Mestrado em Enfermagem Psiquiátrica) Escola de Enfermagem de Ribeirão Preto, Universidade de São Paulo, Ribeirão Preto, 2013.

SILVA, M. M. et al. Percepção das mulheres sobre a assistência pré-natal prestada na colônia penal feminina. Rev enferm UFPE. v. 9, supl. 7, p. 9038-9045, 2015.

SOUZA, M. T.; SILVA, M. D.; CARVALHO, R. Revisão integrativa: o que é e como fazer. Einstein, v. 8, n. 1, p. 102-106, 2010. 